\title{
Relationships Between Milk Culture Results and Milk Yield in Norwegian Dairy Cattle
}

\author{
O. Reksen, ${ }^{* 1}$ L. Sølverød, $†$ and 0. Østerås ${ }^{\star} \dagger$ \\ *Norwegian School of Veterinary Science, Department of Production Animal Clinical Sciences, PO Box 8146, N-0033 Oslo, Norway \\ †TINE BA, PO Box 58, N-1430 Ås, Norway
}

\begin{abstract}
Associations between test-day milk yield and positive milk cultures for Staphylococcus aureus, Streptococcus spp., and other mastitis pathogens or a negative milk culture for mastitis pathogens were assessed in quarter milk samples from randomly sampled cows selected without regard to current or previous udder health status. Staphylococcus aureus was dichotomized according to sparse $(\leq 1,500 \mathrm{cfu} / \mathrm{mL}$ of milk) or rich $(>1,500 \mathrm{cfu} /$ $\mathrm{mL}$ of milk) growth of the bacteria. Quarter milk samples were obtained on 1 to 4 occasions from 2,740 cows in 354 Norwegian dairy herds, resulting in a total of 3,430 samplings. Measures of test-day milk yield were obtained monthly and related to 3,547 microbiological diagnoses at the cow level. Mixed model linear regression models incorporating an autoregressive covariance structure accounting for repeated test-day milk yields within cow and random effects at the herd and sample level were used to quantify the effect of positive milk cultures on test-day milk yields. Identical models were run separately for first-parity, second-parity, and thirdparity or older cows. Fixed effects were days in milk, the natural logarithm of days in milk, sparse and rich growth of Staph. aureus (1/0), Streptococcus spp. (1/0), other mastitis pathogens (1/0), calving season, time of test-day milk yields relative to time of microbiological diagnosis (test day relative to time of diagnosis), and the interaction terms between microbiological diagnosis and test day relative to time of diagnosis. The models were run with the logarithmically transformed composite milk somatic cell count excluded and included. Rich growth of Staph. aureus was associated with decreased production levels in first-parity cows. An interaction between rich growth of Staph. aureus and test day relative to time of diagnosis also predicted a decline in milk production in third-parity or older cows. Interaction between sparse growth of Staph. aureus and test day
\end{abstract}

Received December 28, 2006.

Accepted June 21, 2007.

${ }^{1}$ Corresponding author: Olav.Reksen@veths.no relative to time of diagnosis predicted declining testday milk yields in first-parity cows. Sparse growth of Staph. aureus was associated with high milk yields in third-parity or older cows after including the logarithmically transformed composite milk somatic cell count in the model, which illustrates that lower production levels are related to elevated somatic cell counts in high-producing cows. The same association with testday milk yield was found among Streptococcus spp.positive pluriparous cows.

Key words: subclinical, mastitis, cow, milk yield

\section{INTRODUCTION}

Bacterial culture is routinely used to diagnose mastitis, and culture results are often the basis for evaluating the quality and extent of a problem at the herd level. At the cow level, information about production potential following the isolation of mastitis pathogens is of importance in treatment and culling decisions. In the majority of studies, the focus has mainly been on clinical cases or cases with elevated cell counts when the relationship between mastitis pathogens and milk yield has been assessed (Rajala-Schultz et al., 1999; Gröhn et al., 2004; Wilson et al., 2004). However, a milk culture might test positive by microbiological analysis because of clinical or subclinical mastitis (Harmon, 1994) or because of colonization of the teat canal and cistern, with no major involvement of the mammary parenchyma (Persson et al., 1995). Clinical mastitis has been associated with marked losses in milk yield (Rajala-Schultz et al., 1999; Gröhn et al., 2004), and subclinical IMI, as defined by elevations in composite milk SCC (CMSCC), has been associated with losses in milk yield both during lactation (Miller et al., 2004) and from one lactation to the next (Fetrow et al., 1991). Relatively little is known about the relationship between milk yield and a positive culture of mastitis pathogens when sampling for bacteriological analyses is conducted, irrespective of cowlevel characteristics. Mastitis pathogens isolated in milk cultures from clinically normal animals most likely originate from subclinical IMI or colonization of the udder. 
Staphylococcus aureus is the most frequently isolated mastitis pathogen in Norway (Østerås et al., 2005), and the success in detecting infected cows is related to the number of colony-forming units found by microbiological analysis (Sears et al., 1990). Because isolates with a low number of colony-forming units of Staph. aureus per milliliter of milk are often not reported (Pitkala et al., 2004), there is reason to ask whether there are differences in milk yield between isolates with rich and sparse growths of Staph. aureus sufficient to justify this practice. A relevant question is whether this also applies to microbiological milk cultures obtained, irrespective of udder health characteristics.

The objectives of the present study were to assess milk yield before and after isolation of Staph. aureus, Streptococcus spp., or other mastitis pathogens in a random sample of the Norwegian cow population, and to compare differences in milk yield between cows isolated with sparse $(\leq 1,500 \mathrm{cfu} / \mathrm{mL}$ of milk) and rich $(>1,500 \mathrm{cfu} / \mathrm{mL}$ of milk) growths of Staph. aureus.

\section{MATERIALS AND METHODS}

A survey of quarter milk cultures obtained in 3,538 samplings at the cow level from 354 Norwegian dairy herds was conducted between January 19, 2000, and January 23, 2001. The study population, design of the survey, and laboratory procedures were discussed in detail previously (Østerås et al., 2006). Among all Norwegian dairy farms, $89.2 \%$ were enrolled in the Norwegian Dairy Herd Recording System (NDHRS) at the beginning of the investigation (Østerås, 2002), and the cows in this study were selected from these herds. Both herds and cows were subject to systematic random selection procedures such that every 50th Norwegian dairy herd was selected for sampling and culture from the files of the NDHRS. Cows were sorted according to their unique identity number within a herd, and every fifth cow was selected for microbiological sampling after drawing a starting number from 1 to 4 . The random selection of cows was carried out 4 times (quarterly) during the investigation period to ensure a representative collection from all 4 seasons. Each cow had the same chance of being selected each season.

Quarter milk samples were collected aseptically by trained advisors from the dairy industry. The individual milk samples were analyzed for the growth of microorganisms in accordance with the official procedure in Norway (Aursjø et al., 1993), based on the procedures of the International Dairy Federation $(1981,1987)$, except that isolates of Staph. aureus were categorized according to the number of colony-forming units at the cow level. The amount of Staph. aureus was regarded as rich when $>15$ cfu was found in at least one sample of $0.01 \mathrm{~mL}$ of milk (>1,500 cfu/mL of milk) and was regarded as sparse when $\leq 15$ cfu was found upon microbiological analysis in one or more quarters. The 1,500 $\mathrm{cfu} / \mathrm{mL}$ threshold value between rich and sparse growths of Staph. aureus was chosen because of its use in the official Norwegian procedure of the National Veterinary Institute. Mastitis pathogens were regarded as present when the following microorganisms were isolated from the milk samples: Staph. aureus, Streptococcus dysgalactiae, Streptococcus uberis, other Streptococcus spp., coagulase-negative Staphylococcus spp., coliform bacteria (including Escherichia coli), Enterococcus spp., Arcanobacter pyogenes, and Bacillus spp. Staphylococcus aureus was regarded as present when a coagulase-positive Staphylococcus spp. was diagnosed. More than one diagnosis was assigned at the cow level when a microbiological diagnosis differed between quarters in the same cow.

For herds taking part in the NDHRS, records are maintained on calving date, parity, test-day monthly milk yield, test-day CMSCC (recorded bimonthly), culling, and disease history. Composite milk SCC was measured in milk samples collected from 2 successive milkings by Fossomatic 5000 equipment (Foss Electric, Hillerød, Denmark). This information was merged with data on the outcomes of the microbiological tests. To avoid interfering with management decisions, diagnoses resulting from the microbiological examinations were not reported to the farmer before the study ended. The median herd size in the study was 15.1 cows (range $=3$ to 99). Purebred Norwegian Red cattle constituted $97.7 \%$ of the cow population in the study. The NDHRS lacked unique identification on 76 microbiological samples from 68 cows, and because of missing information for the covariates, the material included in the statistical analyses was reduced to a total of 27,665 test-day milk yield and 13,795 CMSCC observations, which were related to 3,547 microbiological analyses from 3,430 samplings in 2,740 cows. In total, 1,279 cows were sampled only once, 617 cows were sampled twice, 69 cows were sampled 3 times, and 5 cows were sampled 4 times.

\section{Statistical Analyses}

In the present investigation, multiple records on milk yield were used for each individual, and the relationships between the outcome variable (milk yield) and the explanatory variables were assessed by using the mixed model linear regression for repeated outcomes in PROC MIXED of SAS (Littell et al., 1996). Milk yield measurements within the same cow were correlated and accounted for by using a first-order autoregressive correlation structure. Other correlation structures were 
modeled, but the first-order autoregressive correlation structure resulted in the best model fit (Schwartze's Bayesian criterion was closest to zero). Repeated sampling for microbiological milk culture in the same cow and clustering at the herd level were accounted for by including sample number and herd as random effects.

Parity was categorized as first, second, and third parity or older. Test-day milk yield was obtained monthly and included in the models as a continuous outcome variable. Only test-day milk yields up to 305 DIM were used. The natural logarithm of CMSCC (InCMSCC) was used in the analyses. Bimonthly lnCMSCC was entered as a continuous variable. The lactation curve was expressed through the inclusion of DIM and the natural logarithm of DIM (InDIM) in the model (Wilmink, 1987).

The time of test-day milk yields relative to the time of microbiological diagnosis was categorized within 5 time periods before and after microbiological diagnosis. The first period yielded estimates for test-day milk yields obtained earlier than 3 mo before microbiological diagnosis. The next category estimated milk yields for the second and third months before diagnosis. The third period expressed milk yields for the period including the month before and the month after diagnosis. Thereafter, milk yield estimates for the second and third month, and finally estimates for milk yields later than 3 mo after diagnosis were predicted.

Previous mastitis history was tested as a) a dichotomous variable reflecting whether a cow had been treated for clinical mastitis before it was sampled for microbiological analysis during the current and the preceding lactation, and $b$ ) whether a cow had been treated for clinical mastitis before sampling during the current lactation. Calving season and season of microbiological diagnosis were grouped quarterly into winter, spring, summer, and fall.

The backward selection procedure was applied, and the variable with the highest $P$-value was omitted. The model was rerun each time a variable was omitted. Variables with $P \leq 0.10$ in 1 of the 3 parity-specific models remained in all models for the comparison. The covariates of season of microbiological diagnosis, mastitis histories a) and b), the cross-product between microbiological diagnosis and DIM, and the cross-product between microbiological diagnosis and lnCMSCC were omitted from the final models. Because the relationship between milk yield and a positive milk culture is expected to change over time (Gröhn et al., 2004), milk weights were divided into several periods, both pre- and postdiagnosis, according to when they were measured in relation to microbiological diagnosis. To describe this pathogen- and parity-specific relationship, the interaction term between microbiological diagnosis and time relative to diagnosis was entered into all models, regardless of the significance level.

After the main model was created by using the backward selection procedure, an additional procedure was conducted to assess whether the number of microbiologically positive quarters was related to milk yield. Each positive milk culture was categorized with 4 levels, according to the number of infected quarters. Microbiologically negative cows were the reference group and were assigned a value of 0 . Because no additional information was obtained at the level of one category per microbiologically positive quarter in either parity, the categories representing 3 and 4 microbiological quarters were collapsed into one category. However, no additional information was obtained when categorizing the number of microbiological quarters as 1,2 , or 3 and more infected quarters. In addition, categorizing quarters into 2 groups representing one and more than one infected quarters did not improve the model, such that only pathogen-specific dichotomous variables remained in the model.

Fixed effects in the final model were DIM, lnDIM, sparse growth of Staph. aureus (1/0), rich growth of Staph. aureus (1/0), Streptococcus spp. (1/0), other pathogens (1/0), calving season, time of test-day milk yields relative to time of microbiological diagnosis (test day relative to time of diagnosis), and interaction terms between microbiological diagnosis and test day relative to time of diagnosis. The models were run with lnCMSCC excluded and included. Overall statistical significance was assessed by a type III $F$-test. In all analyses, statistical significance was considered as a $P$ value of 0.05 or less.

\section{RESULTS}

\section{Microbiological Diagnoses}

The distribution of 3,547 microbiological diagnoses, as obtained from 3,430 milk samples at the cow level, is presented in Table 1. None of the samples was positive for Streptococcus agalactiae.

\section{Relationships Between Microbiological Diagnoses and Milk Yield}

The type III $F$-test assessing the impact of the covariates is presented separately for each parity group in Table 2 together with the significance level and parameter estimates of the main effects. Parameter estimates of the interaction between microbiological diagnosis and test day relative to time of diagnosis are reported in Table 3.

Staph. aureus. Relative to the main effect of sparse growth of Staph. aureus (Table 2), the interaction be- 
Table 1. Distribution of microbiological diagnoses ${ }^{1}$

\begin{tabular}{|c|c|c|c|}
\hline Microbiological diagnosis & $\begin{array}{l}\text { First parity, } \\
\mathrm{n}=1,436(\%)\end{array}$ & $\begin{array}{l}\text { Second parity } \\
\mathrm{n}=966(\%)\end{array}$ & $\begin{array}{c}\geq \text { Third parity, } \\
\mathrm{n}=1,145(\%)\end{array}$ \\
\hline No pathogens & $929(65)$ & $615(64)$ & $671(59)$ \\
\hline$\leq 1,500 \mathrm{cfu} / \mathrm{mL}$ of milk of Staphylococcus aureus ${ }^{2}$ & $162(11)$ & $105(11)$ & $147(13)$ \\
\hline Streptococcus dysgalactiae, Streptococcus uberis, and other Streptococcus spp. & $45(3)$ & $52(5)$ & $80(7)$ \\
\hline Coagulase-negative Staphylococcus spp. & $131(9)$ & $103(11)$ & $124(11)$ \\
\hline Other pathogens ${ }^{3}$ & $11(1)$ & $9(1)$ & $16(1)$ \\
\hline
\end{tabular}

${ }^{1}$ Quarter milk samples were obtained in a total of 3,430 samplings, generating 3,547 microbiological diagnoses at the cow level.

${ }^{2}$ Coagulase-positive Staphylococcus spp. categorized as rich (>1,500 cfu/mL of milk) or sparse ( $\leq 1,500 \mathrm{cfu} / \mathrm{mL}$ of milk) growth of the bacteria.

${ }^{3}$ Enterococcus spp., Arcanobacter pyogenes, Bacillus spp., and coliform bacteria, including Escherichia coli.

tween sparse growth of Staph. aureus and test day relative to time of diagnosis predicted a peak in production level during the 2- to 3-mo period prior to microbiological milk culture, followed by a declining production level during the following lactation months in first-parity cows (Table 3, Figure 1). No association with milk yield was apparent in second-parity cows diagnosed positive for sparse growth of Staph. aureus (Table 2). Sparse growth of Staph. aureus was associated with increased production levels in third-parity or older cows after inclusion of $\operatorname{lnCMSCC}$ in the model (Table 2). This effect was lower and nonsignificant when InCMSCC was not included.

Rich growth of Staph. aureus was associated with decreased production levels in first-parity cows (Table 2; Figure 1). The same numerical tendency was also apparent among second-parity cows (Table 2). Relative to the main effect of rich growth of Staph. aureus (Table 2 ), the interaction term between rich growth of Staph. aureus and test day relative to time of diagnosis was associated with decreases in production level in thirdparity or older cows (Table 3).

Streptococcus spp. Positive milk cultures for Streptococcus spp., as assessed by the model main effect, were associated with increased production levels in secondparity cows (Table 2). This effect increased when lnCMSCC was included in the model. The same relationship was significant in third-parity or older cows only after inclusion of lnCMSCC in the model (Table 2).

Other Mastitis Pathogens. Relative to the main effect (Table 2), the interaction between other mastitis pathogens and test day relative to time of diagnosis was associated with decreases in production level in first-parity cows after inclusion of $\operatorname{lnCMSCC}$ in the model (Table 3). A positive milk culture for other pathogens was associated with decreased production levels in second-parity cows after inclusion of lnCMSCC in the model (Table 2). No association between milk yield and other pathogens was observed among third-parity or older cows (Table 2).

\section{Calving Season}

Relative to milk production during the fall quarter, milk production during winter, spring, and summer was lower. Second-parity cows showed a nadir in milk production during summer, whereas the lowest production was found during the spring quarter for the other 2 parity groups (Table 2 ).

\section{Cow CMSCC}

The natural logarithm of CMSCC was significantly and inversely related to milk yield for all parity groups.

\section{Time of Test-Day Milk Yields Relative to Time of Microbiological Diagnosis}

Test-day milk yields declined in a linear mode in all parity groups throughout the period before and after microbiological milk culture, although the effect was significant only for third-parity or older cows (Table 2). The interaction with microbiological diagnosis revealed a higher production level in a number of the combinations of parity group and microbiological diagnosis before diagnosis and a successive decline in production level after diagnosis relative to cows that tested negative by the milk culture (Table 3 ).

\section{DISCUSSION}

\section{Microbiological Diagnoses}

The prevalence of positive milk cultures for Staph. aureus was higher in the present investigation than in a recent, and comparable, Finnish investigation (Pitkala et al., 2004; Østerås et al., 2006). The difference in prevalence between the Norwegian and Finnish study may be because isolates with sparse growth of Staph. aureus were not reported in the latter (Pitkala et al., 2004), whereas all isolates of Staph. aureus were included in our sampled material. This motivated us to investigate whether there are differences in milk yield 
Table 2. Estimates $(\beta)$ of test-day milk yields (kg) reported for DIM, the natural logarithm of DIM (lnDIM), diagnosis upon microbiological milk culture, time of test-day milk yields relative to microbiological diagnosis, and calving season ${ }^{1}$

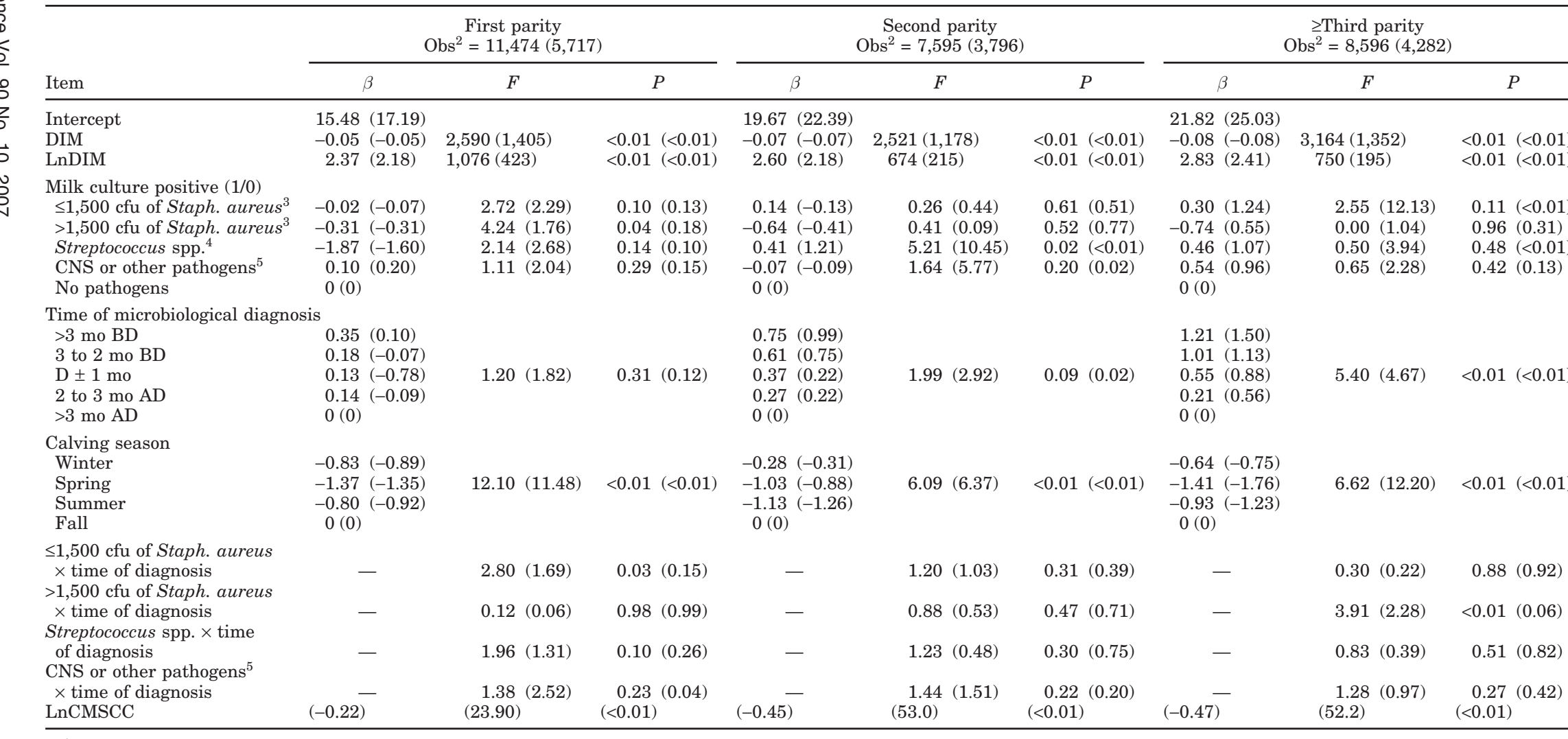

${ }^{1}$ Test-day milk yields relative to microbiological diagnosis were categorized in months before (BD) and after (AD) microbiological diagnosis (D). Estimates from models with the natural logarithm of the composite cow SCC (lnCMSCC) included as covariate are given in parentheses. Overall $F$-values and $P$-levels are reported for the type III test. Estimates for the crossproduct between time of microbiological diagnosis and milk culture results are reported in Table 3. Mixed model linear regression for repeated outcomes in PROC MIXED of SAS (Littell et al., 1996) was used separately for each of the parity categories (first parity, second parity, and later than second parity).

${ }^{2}$ Observations used for the estimation.

${ }^{3}$ Coagulase-positive Staphylococcus spp. categorized as rich ( $>1,500 \mathrm{cfu} / \mathrm{mL}$ of milk) or sparse $(\leq 1,500 \mathrm{cfu} / \mathrm{mL}$ of milk) growth of the bacteria.

${ }^{4}$ Streptococcus dysgalactiae, Streptococcus uberis, other Streptococcus spp.

${ }^{5}$ Coagulase-negative Staphylococcus spp.; coliform bacteria, including Escherichia coli, Enterococcus spp., Arcanobacter pyogenes, and Bacillus spp. 


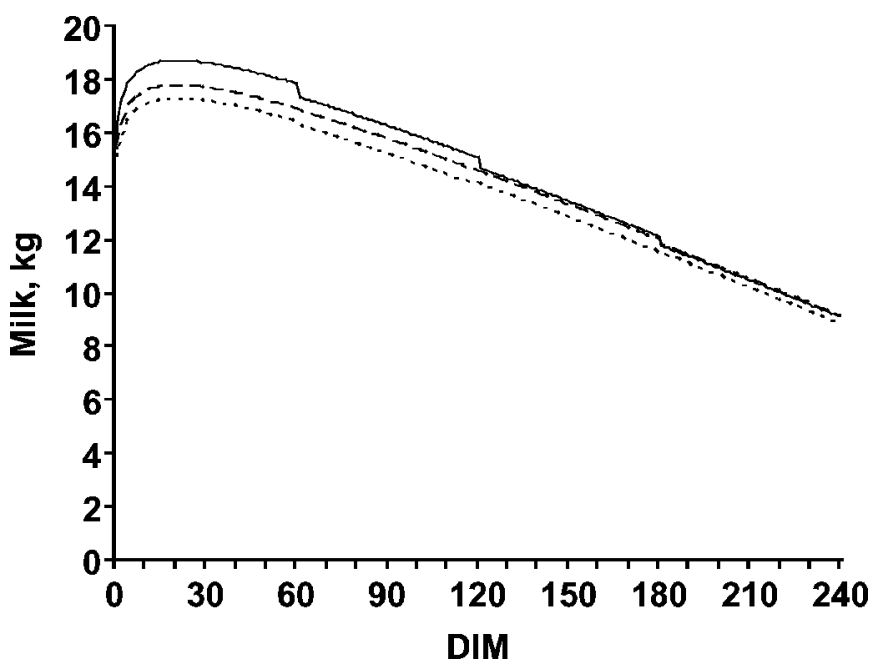

Figure 1. Predicted test-day milk yield (kg/d) by DIM in firstparity cows with a positive milk culture for sparse growth of Staph. aureus (solid line) or rich growth of Staph. aureus (dotted line), or a negative culture for mastitis pathogens (dashed line). Milk cultures were obtained at 90 DIM. Coagulase-positive Staphylococcus spp. were categorized as rich $(>1,500 \mathrm{cfu} / \mathrm{mL}$ of milk) or sparse $(\leq 1,500$ $\mathrm{cfu} / \mathrm{mL}$ of milk) growth of the bacteria.

between cows with rich positive culture growth of Staph. aureus as opposed to those with sparse growth (Aursjø et al., 1993). A more detailed discussion of the microbiological diagnoses and cluster effects in the current study can be obtained from Østerås et al. (2006).

\section{Relationships Between Microbiological Diagnoses and Milk Yield}

The covariates of monthly milk yield, bimonthly lnCMSCC, and parity were all obtained at the cow level. Microbiological analyses were conducted at the quarter level. Because the NDHRS does not have records on these variables at the quarter level, comparisons between microbiological diagnoses and milk yield were conducted at the cow level. This limitation should be taken into account when the findings of the study are interpreted. Subclinical IMI has been defined as an infection with no visible changes in the appearance of the milk or the mammary gland, but in which milk production decreases, bacteria are present in the secretion, and inflammatory changes in the milk can be detected by special tests, such as a cell count (Harmon, 1994; National Mastitis Council, 1996). A number of the isolates of mastitis pathogens revealed in the present study would come under this definition. We also expect a considerable number of the isolates of mastitis pathogens in the present investigation to exist because of colonization of the teat canal and cistern along with no or only limited inflammatory responses. Clinical masti- 
tis is characterized by abnormal milk, which may be accompanied by swelling or pain in the udder and systemic signs such as elevated rectal temperature, lethargy, or anorexia (Harmon, 1994; National Mastitis Council, 1996). Even though some of the cows may have had clinical signs at the time of diagnosis, we expected the number of clinical cases of mastitis to be negligible in the present investigation because random sampling procedures had been followed.

Staph. aureus. The present investigation revealed an association between milk yield and Staph. aureus comparable to that previously described for clinical mastitis, because microbiologically positive cows were higher producers than noninfected herdmates prior to diagnosis (Gröhn et al., 2004). Both sparse and rich growths of Staph. aureus were associated with decreased milk production in first-parity cows. Rich growth of the bacteria generally was associated with a lowered production level. For sparse growth of Staph. aureus, a pattern of declining milk yields from peak production before diagnosis to low levels after diagnosis was identifiable in first-parity cows with a positive milk culture (Figure 1). This difference may indicate a more chronic subclinical IMI in first-parity cows when Staph. aureus was abundant, and a more recent IMI when a smaller amount of the bacteria was found upon microbiological milk culture.

Inclusion of lnCMSCC in the model showed only minor alterations of the milk yield estimates associated with Staph. aureus in first-parity cows. Third-parity or older cows with a positive diagnosis for sparse growth of Staph. aureus produced significantly more milk than herdmates without this characteristic after adjustments had been made for lnCMSCC. This finding indicates that high yields are associated with Staph. aureus, and that sparse growth of Staph. aureus is also related to elevated cell counts. Third-parity or older cows diagnosed positive for rich growth of Staph. aureus experienced a sharp decline in milk yield from peak production before diagnosis to low levels after diagnosis. In addition, among cows with this characteristic, lnCMSCC accounted for an important fraction of the milk loss. This is not surprising because Staph. aureus often induces subclinical IMI, with loss of udder parenchyma and persistently high SCC, especially in older cows (Harmon, 1994).

Variation in the number of colony-forming units not only reflects the degree of IMI, but also indicates fluctuation in the shedding of the bacteria over time (Sears et al., 1990). This may explain why losses in milk yield were significant among low-shedding first-parity cows in the present investigation. Sears et al. (1990) were unable to detect differences in SCC between groups of experimentally infected cows that shed less than 1,000 and more than 2,000 cfu of Staph. aureus/mL of milk. The same study concluded that $40 \%$ of cows shedding an average of less than 1,000 cfu of Staph. aureus/mL would be missed by one single bacteriological culture based on the inoculation of $0.01 \mathrm{~mL}$ of quarter milk (Sears et al., 1990). Taken together, there are strong indications that useful information may be lost if isolates with sparse growth of the bacteria are not included when the prevalence of Staph. aureus is reported.

More recently, treatments for subclinical IMI have been advocated (Oliver et al., 2004; Swinkels et al., 2005), and both the incidence and duration of subclinical IMI caused by Staph. aureus may be favorably influenced by treatment during lactation (Sol et al., 1997; Oliver et al., 2004). Treatment success is higher in second-parity and younger cows than among third-parity and older cows (Sol et al., 1997). This correlates well with the present study in that losses in milk yield attributable to subclinical IMI in first-parity cows were less influenced by CMSCC than those in older Staph. aureus-positive cows. In view of an increased likelihood of more chronic subclinical IMI in older cows, the benefit of treatment would be higher when restricted to cows in their first and second lactation. However, even with this restriction it is questionable whether increased production would warrant the economic loss caused by discharge of milk and treatment costs.

Decreases in milk production after diagnosis were found for cows with both rich and sparse growths of Staph. aureus. The association between culling and a positive culture for mastitis pathogens has recently been evaluated. A high probability of culling was observed among cows diagnosed with a rich growth of Staph. aureus (Reksen et al., 2006), whereas cows showing a sparse growth of the bacteria were more likely to be treated for clinical mastitis. A high likelihood of culling has also been associated with older cows and with increasing CMSCC (Reksen et al., 2006). Therefore, the current estimates of losses in milk yield may be slightly underestimated for older cows, cows with high CMSCC, and cows with a rich growth of Staph. aureus.

Streptococcus spp. Although the observed decline in milk production in first-parity cows was not significantly associated with Streptococcus spp., attention may be drawn to the inverse relationship between firstparity and pluriparous cows positive for Streptococcus spp. An increased production level was observed in Streptococcus spp.-positive second-parity cows. The same relationship was significant in third-parity or older cows after correction for lnCMSCC. This is in contrast to earlier findings in studies of clinical IMI, in which a large drop in production was associated with clinical mastitis because of Streptococcus spp. in third- 
parity or older cows, but not in younger cows (Gröhn et al., 2004). This may reflect the fact that high-producing pluriparous cows are highly susceptible to subclinical IMI caused by Streptococcus spp., and the potential loss in milk yield is large in this group when it progresses to clinical IMI. This notion is supported by the fact that predicted milk yields were higher in pluriparous cows after correction for the effect of lnCMSCC. The models without adjustment for lnCMSCC predicted lower yields, because the combined effect of Streptococcus spp. and corresponding elevations in cell count were assessed in these models. Thus, increases in cell counts attributable to clinical streptococci mastitis are likely to have a large impact on milk yield in pluriparous cows, whereas numerical losses in milk yield were observed in subclinical cases of IMI in first-parity cows of the current study.

Other Mastitis Pathogens. The associations between other mastitis pathogens and milk yield must largely be attributed to coagulase-negative Staphylococcus spp., which constituted the vast majority of microbiological diagnoses defined as other pathogens in the current study. Correction for lnCMSCC in the models assessing associations between milk yield and Staph. aureus or Streptococcus spp. tended to increase estimates of milk production. However, the reverse was observed in cows positive for other pathogens in that more pronounced decreases in milk yields were predicted in second-parity cows after inclusion of lnCMSCC. This was presumably because a positive diagnosis of other pathogens was associated only with minor or no inflammatory responses. The negative relationship with milk production that was found among second-parity cows in this investigation was too low to warrant antimicrobial treatment, even though Oliver et al. (2004) showed relatively high cure rates for subclinical IMI caused by microorganisms that were classified as other pathogens in the current investigation. We hypothesize that a positive diagnosis of other pathogens in third-parity or older cows may be due to subclinical IMI and the persistence of bacteria from one lactation to the next (Fetrow et al., 1991).

\section{Cow CMSCC}

The association between positive milk cultures and CMSCC is well documented (Harmon, 1994; de Haas et al., 2004), and adjustment for lnCMSCC in the model may conceal associations between culture results and the outcome variable that would otherwise become apparent. Therefore, results from models without the lnCMSCC included have been emphasized in this study. However, to account for the degree of inflammatory response, the lnCMSCC value that corresponded in time to the current measure of milk yield was also included in the analyses. Even though the models with and without lnCMSCC included as a covariate have different sample sizes, we feel confident that the present investigation also gives a reasonable estimate of the impact of a positive milk culture for mastitis pathogens on milk production after correction for lnCMSCC in Norwegian cattle.

The direction of changes in milk yield by lnCMSCC was in line with previous reports, even though the magnitude was lower than reported for the Holstein breed (Miller et al., 2004). This is probably because Norwegian Red cattle produce less milk than HolsteinFriesian cattle and that farmers emphasize CMSCC when selecting cows for breeding, because milk price premiums are paid for bulk milk tank SCC $<230,000$ cells/mL of milk in Norway.

\section{Calving Season}

The highest milk production was observed during the fall for all parities. This is probably related to the fact that most births occur during late summer and early fall (Roalkvam, 2005) and the fact that harvested forage is at its best during fall and early winter.

\section{CONCLUSIONS}

The appearance of mastitis pathogens in milk samples from a random sample of the cow population revealed relationships between microbiological diagnosis and milk yield similar to those previously reported from clinical IMI. Although the magnitude of the associations was smaller than reported from clinical cases of mastitis, the significant relationships were surprising in that one would have expected a high level of transient colonization of the teat canal and cistern with a minor impact on production in the cows of this study. It is also worth noting that the loss in milk production capacity was comparable between Staph. aureus-positive cows with rich and sparse numbers of colony-forming units. Viewed as a whole, the present study indicates that a positive diagnosis of Staph. aureus and Streptococcus spp., according to microbiological milk analysis of clinically normal cows, correlates with future production potential.

\section{ACKNOWLEDGMENTS}

This study was supported by a grant from the Research Council of Norway (Oslo, Norway). We thank the advisors at TINE Norwegian Dairies for supplying us with all milk samples. Access to production and health data was given by the Norwegian Dairy Herd 
Recording System and the Norwegian Cattle Health Services (Ås, Norway) in agreement number 1 in 2002. We would like to thank Ralph Nash at Nash Project Services (Kristiansand, Norway) for his assistance in editing this manuscript.

\section{REFERENCES}

Aursjø, J., D. Lindheim, O. Reksen, T. Skjervheim, T. Slettbakk, L. Sølverød, and S. Waage. 1993. Laboratorierutiner for mastittdiagnostikk ved Statens veterinære laboratorier (Laboratory Routines at the State Veterinary Laboratories). Statens Veterinære Laboratorier, Oslo, Norway.

De Haas, Y., R. F. Veerkamp, H. W. Barkema, Y. T. Gröhn, and Y. H. Schukken. 2004. Associations between pathogen-specific cases of clinical mastitis and somatic cell count patterns. J. Dairy Sci. 87:95-105.

Fetrow, J., D. Mann, K. Butcher, and B. McDaniel. 1991. Production losses from mastitis: Carry-over from the previous lactation. J. Dairy Sci. 74:833-839.

Gröhn, Y. T., D. J. Wilson, R. N. Gonzalez, J. A. Hertl, H. Schulte, G. Bennett, and Y. H. Schukken. 2004. Effect of pathogen-specific clinical mastitis on milk yield in dairy cows. J. Dairy Sci. 87:3358-3374.

Harmon, R. J. 1994. Physiology of mastitis and factors affecting somatic cell counts. J. Dairy Sci. 77:2103-2112.

International Dairy Federation. 1981. Laboratory Methods for Use in Mastitis Work. IDF Bull. 132. Int. Dairy Fed., Brussels, Belgium.

International Dairy Federation. 1987. Bovine Mastitis. Definition and Guidelines for Diagnosis. IDF Bull. 211:1987. Int. Dairy Fed., Brussels, Belgium.

Littell, R. C., G. A. Milliken, W. W. Stroup, and R. D. Wolfinger. 1996. SAS System for Mixed Models. 1st ed. SAS Institute Inc., Cary, NC.

Miller, R. H., H. D. Norman, G. R. Wiggans, and J. R. Wright. 2004. Relationship of test-day somatic cell score with test-day and lactation milk yields. J. Dairy Sci. 87:2299-2306.

National Mastitis Council. 1996. Current Concepts of Bovine Mastitis. Natl. Mastitis Counc., Madison, WI.

Oliver, S. P., B. E. Gillespie, S. J. Headrick, H. Moorehead, P. Lunn, H. H. Dowlen, D. L. Johnson, K. C. Lamar, S. T. Chester, and W. M. Moseley. 2004. Efficacy of extended ceftiofur intramammary therapy for treatment of subclinical mastitis in lactating dairy cows. J. Dairy Sci. 87:2393-2400.

Østerås, O. 2002. The health card annual report 2001 (Helsekortordninga 2001). Nor. Vet. Tidsskr. 114:481-492.

Østerås, O., K. P. Forshell, N. E. Svendsby, L. E. Ruud, and A. O. Refsdal. 2005. Norwegian Dairy Herd Recording System (NDRHS) Annual Statistics (Arsrapport, Helsetjenesten for storfe). Norwegian Dairy Herd Recording System, As, Norway.

Østerås, O., L. Solverod, and O. Reksen. 2006. Milk culture results in a large Norwegian survey, effects of season, parity, days in milk, resistance, and clustering. J. Dairy Sci. 89:1010-1023.

Persson, K., B. Amolina, and P. Jonsson. 1995. Inflammation in the bovine teat cistern induced by Staphylococcus aureus. Zentralbl. Veterinarmed. B. 42:435-442.

Pitkala, A., M. Haveri, S. Pyorala, V. Myllys, and T. HonkanenBuzalski. 2004. Bovine mastitis in Finland 2001, prevalence, distribution of bacteria, and antimicrobial resistance. J. Dairy Sci. 87:2433-2441.

Rajala-Schultz, P. J., Y. T. Gröhn, C. E. McCulloch, and C. L. Guard. 1999. Effects of clinical mastitis on milk yield in dairy cows. J. Dairy Sci. 82:1213-1220.

Reksen, O., L. Solverod, A. J. Branscum, and O. Østeras. 2006. Relationships between milk culture results and treatment for clinical mastitis or culling in Norwegian dairy cattle. J. Dairy Sci. 89:2928-2937.

Roalkvam, T. 2005. Tine, Annual Statistics 2004 (Tine produsentrådgivning, Statistikksamling 2004). Tine Produsenntrådgivning, As, Norway.

Sears, P. M., B. S. Smith, P. B. English, P. S. Herer, and R. N. Gonzalez. 1990. Shedding pattern of Staphylococcus aureus from bovine intramammary infections. J. Dairy Sci. 73:2785-2789.

Sol, J., O. C. Sampimon, J. J. Snoep, and Y. H. Schukken. 1997. Factors associated with bacteriological cure during lactation after therapy for subclinical mastitis caused by Staphylococcus aureus. J. Dairy Sci. 80:2803-2808.

Swinkels, J. M., H. Hogeveen, and R. N. Zadoks. 2005. A partial budget model to estimate economic benefits of lactational treatment of subclinical Staphylococcus aureus mastitis. J. Dairy Sci. 88:4273-4287.

Wilmink, J. B. M. 1987. Adjustment of test-day milk, fat and protein yield for age, season and stage of lactation. Livest. Prod. Sci. 16:335-348

Wilson, D. J., R. N. Gonzalez, J. Hertl, H. F. Schulte, G. J. Bennett, Y. H. Schukken, and Y. T. Gröhn. 2004. Effect of clinical mastitis on the lactation curve: A mixed model estimation using daily milk weights. J. Dairy Sci. 87:2073-2084. 